\title{
Isolation and characterization of probiotic Bacillus subtilis SKO9 from dairy effluent
}

\author{
G. Sreekumar ${ }^{1}$ and Soundarajan Krishnan ${ }^{2}$ \\ ${ }^{1}$ Department of Biotechnology, St. Joseph's College of Engineering, Chennai-600119, India \\ ${ }^{2}$ Department of Chemical Engineering, Sathyabama University, Chennai-600119, India
}

goodsreekumar@gmail.com

\begin{abstract}
Health promoting microorganisms such as probiotics are recently been used as food additive and therapeutic supplement especially as enhancer of prophylaxis and digestion. Here we report the isolation and characterization of a probiotic bacillus species, with the ability to ferment lactose, from dairy effluent. Biochemical test and 16S rRNA sequencing were done in order to establish the species and strain details. The species was found to be Bacillus subtilis SK09 with a unique ability to ferment lactose. The strain was also subjected to commonly available antibiotics for its antibiotic susceptibility for its probiotic credibility.
\end{abstract}

Keywords: Probiotic bacteria, Bacillus subtilis, lactose intolerance, 16SrRNA sequencing.

Introduction

Recent developments in the field of microbiology as led to the use of human friendly microorganism such as probiotics for the consumption as food additive and a therapeutic (Conway et al., 1987; Fuller, 1994; FAO/WHO, 2002; Donkor et al., 2006). Probiotics are live microorganisms which when administrated in adequate amounts confer to health benefit or nutrition of the host by improving the intestinal microbial balance (Fuller, 1994; FAO/WHO, 2002). Various bacterial strains such as: Bifidobacterium, Lactobacillus and Streptococcus genera as well as yeast of Saccharomyces species. The majority of commercially available probiotic formulations contain Lactobacilli as opposed to Bifidobacteria as the former are more tolerant and more stable in food products. But lactobacilli viability in the stomach is greatly affected by its inability to form spore and endure the acidic environment of the stomach (Crittenden et al., 1996; Begley et al., 2006). Therefore the use of Lactobacillias a probiotic is limited to the confines of it being used as the therapeutic prophylaxis alone rather than being a digestion enhancer.

The term lactose intolerance describes the inability to digest significant amount of lactose resulting from the shortage of enzyme lactase, which is normally produced by the cell that line the walls of small intestine (Kim et al., 1983; De Vrese, 2001). It is estimated that over $75 \%$ of adults worldwide incur lactose intolerance (LT) or lactose malabsorbtion as they get older (Pribila et al., 2000).
Probiotics which can help LT people were developed by various researchers in the past decades like Lactobacillus delbrueckii (Lin et al., 1998), which lacked the efficiency to colonize the lower gut because of their inability to form spores. Studies testing the multi-probiotic product VSL\#3 also fail to improve mal-digestion (Szilagyi et al., 2007). The case of lactose malabsorbtion is persistent problem for the development of potentially successful probiotics which should help the aforementioned people. Therefore it is the need of the hour to isolate a bacterial strain which is capable enough to be used as a probiotic that can ferment lactose and to have the ability to form spores. A probiotic which can be given as a supplement to lactose intolerant people to enhance their digestion of dairy products would be of a good economic and therapeutic value.

In this study we have successfully isolated a new strain of spore forming Bacilli that is capable of fermenting lactose from dairy effluents, since microorganisms isolated from dairy effluents are generally regarded as safe (GRAS). The organism was isolated and tested for its lactose fermenting ability through X-gal plates and $\beta$-galactosidase assay. The isolates were tested for its phenotypic and genotypic characteristics; they were subjected to an array of common antibiotics in order to analyze their probiotic characteristics. Further, 16SrRNA sequencing was performed in order to establish phylogenetic relationship and species specificity. 


\section{Materials and methods}

The primary clarifier effluent generated at Aavin dairy industry, Chennai was collected in sterile sampling vials. $1 \mathrm{ml}$ of the above sample was serially diluted in $9 \mathrm{ml}$ of sterile $0.8 \%$ saline. Dilutions up to $10^{-7}$ were achieved and plates corresponding to $10^{-3}, 10^{-5}$ and $10^{-7}$ were plated on nutrient agar plates infused with $50 \mu \mathrm{l} \mathrm{X-gal} \mathrm{(5-}$ bromo-4-chloro-3-indoxyl- $\beta$-d-galactopyranoside) in order to select colonies with lactose fermenting ability. $20 \mathrm{mg}$ of X-gal (Chempure, India) in $1 \mathrm{ml}$ of $\mathrm{N}$, N-dimethyl formamide solution was used for the above plate. The plates were incubated at room temperature for $24 \mathrm{~h}$. After $24 \mathrm{~h}$ the plates were observed for CFUs with blue colourations indicating the presence of $\beta$-galactosidase producing organisms. Each blue colony was isolated and plated separately as pure cultures in nutrient agar medium. In order to isolate only spore forming bacteria from the lactose fermenters one loopful of pure culture of isolates were then inoculated to $50 \mathrm{ml}$ of sterile Difco sporulation medium (DSM) (Nicholson \& Setlow, 1990) in $250 \mathrm{ml}$ erlenmeyer flask and maintained at $37^{\circ} \mathrm{C}$ for $48 \mathrm{~h}$ at $150 \mathrm{rpm}$. Each of the cultures was tested for spore formation under microscopic observation using SchaefferFulton staining technique (Harley \& Prescott, 2002). Those strains with spore forming ability further characterized for genotyping and phenotyping studies.

\section{Phenotyping}

The isolated pure culture from above steps was subjected to morphological studies and biochemical tests as recommended by Sneath et al. (1986). An identification key proposed by Reva et al. (2001) was used for identification.

\section{$16 S$ rDNA sequencing}

Genomic DNA from the above isolated strain was prepared as described by William et al. (2000). The $16 S$ rDNA gene fragments were amplified by PCR using:

16s forward primer: 5'-AGAGTRTGATCMTYGCTWAC-3' and

16s Reverse Primer: 5'-CGYTAMCTTWTTACGRCT-3'

In an automated thermo cycler (eppendorf mastercycler) which amplify the maximum number of nucleotides in 16S rDNA from a wide variety of bacterial taxa (Hyronimus et al., 1998). PCR reaction and DNA sequencing were performed by William et al. (2000) in an automated gene sequencer (ABI 3130 genetic analyzer). Databases (GenBank) were searched for sequences similarly to the 16S rDNA sequences obtained and a phylogenetic tree was established in correlation with other closely related bacterial stains (Weisburg et al., 1991; Wiley et al., 1991).

\section{Antibiotic resistance analysis}

Antibiotic susceptibility for strains were analyzed by using the disc diffusion method according to the recommendations of the national committee for clinical laboratory standards (Wayne, 1997). Cells from the $48 \mathrm{~h}$ old cultures were diluted1:20 and $100 \mu \mathrm{l}$ was seeded on nutrient agar plates using a swab. Antibiotic-impregnated discs (Himedia, India) were placed on seeded plates and the zone of growth inhibition was measured after $24 \mathrm{~h}$ of incubation at $37^{\circ} \mathrm{C}$.

\section{Fig. 1. Blue-white colonies}

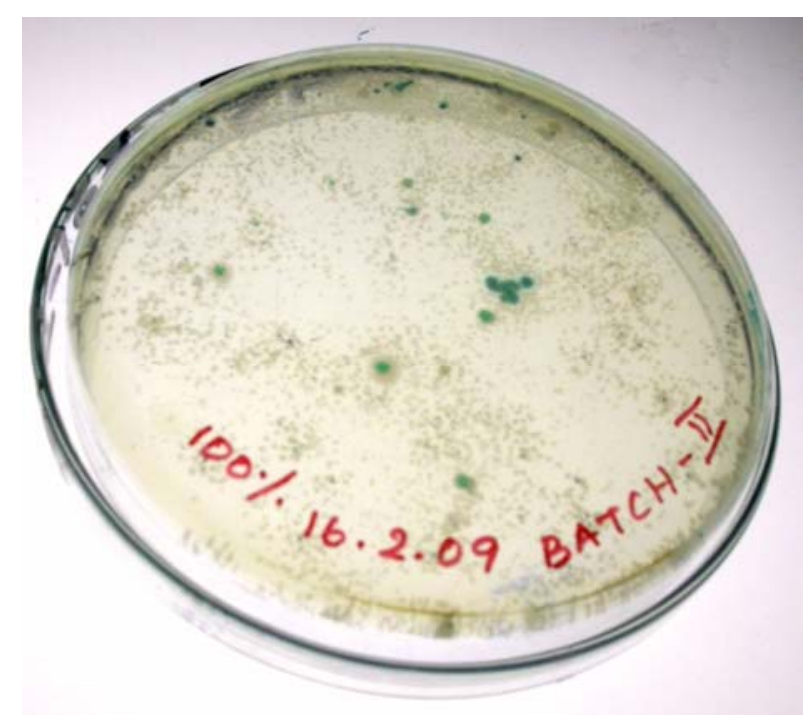

\section{Results}

Isolation and characterization of probiotic Bacillus subtilis SKO9

Clear blue colonies of were observed (Fig. 1) on the $X$-gal plates indicating the presence of lactose fermenting organisms. Individual colonies cultured in sporulation media resulted with only one strain with spore forming ability. The morphology of the above strain of bacteria was: individual motile, gram positive Bacilli, with elliptical endospores which formed flat and circular colonies with undulate margins. The biochemical tests on pure culture of the above strain revealed that it is aerobic organism showing positive results on oxidase and catalase test. The organism was able to metabolize glucose into organic acids and hence gave positive results for methyl red test. In the same way the organism does use butylene glycol pathway and thereby production of acetoin was
Research article

CIndian Society for Education and Environment (iSee)
Sreekumar \& Krishnan Indian J.Sci.Technol. 
observed in Voges proskauer test. The organism can utilize citrate as a substrate and test positive for citrate test. The organism also has an ability to convert nitrate to nitrite and lacks the ability to convert tryptophan into Indole.

Fig. 2. a. Amplified PCR product,

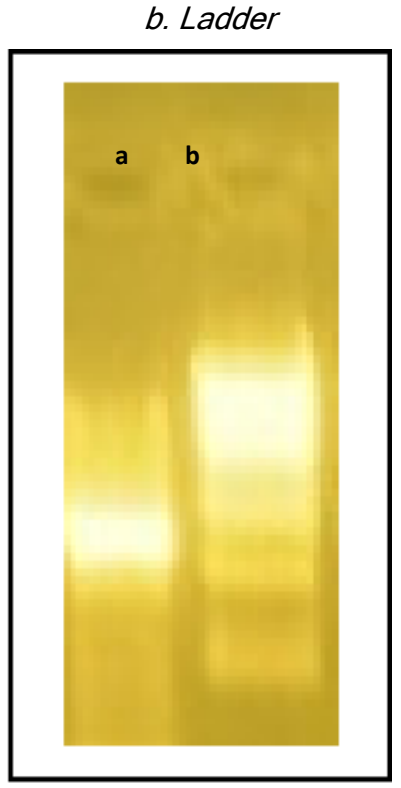

The amplified PCR product is shown in Fig.2. The 16s rRNA sequencing revealed that the organism was 0.999 related to Bacillus subtilis subsp. subtilis GB11; It was proved that it is a unique strain of $B$. subtilis with the ability to ferment lactose and produces $\beta$-galactosidase. The phylogenetic tree of the organism was constructed in accordance with previous reports (Weisburg et al., 1991) (Fig.3). The probiotic spore forming Bacilli was tested for its antibiotic susceptibility with antibiotic discs and results are tabulated in Table 1.

\section{Discussion}

The isolation of a spore forming probiotic Bacilli sp. was successful which had extraordinary abilities to ferment lactose. The biochemical tests were not decisive in defining the exact strain of microorganism as no previous reports of a spore forming Bacilli sp. with a lactose fermenting ability was reported. The 16SrRNA sequencing revealed the strain to be Bacillus subtlis closely related to Bacillus subtilis subsp. subtilis GB11, which is the first of its kind to be ever reported to have lactose fermenting ability at room temperature. Previous reported strain Bacillus subtilis KL88 (Khalid et al., 1991) has a similar ability to ferment lactose at temperatures ranging between $0-10^{\circ} \mathrm{C}$. We acclaim this special ability of fermenting lactose at room temperature by $B$. subtilis to its source of isolation dairy effluent. Over a period of time

Fig. 3. The phylogenetic tree of Bacillus subtilis

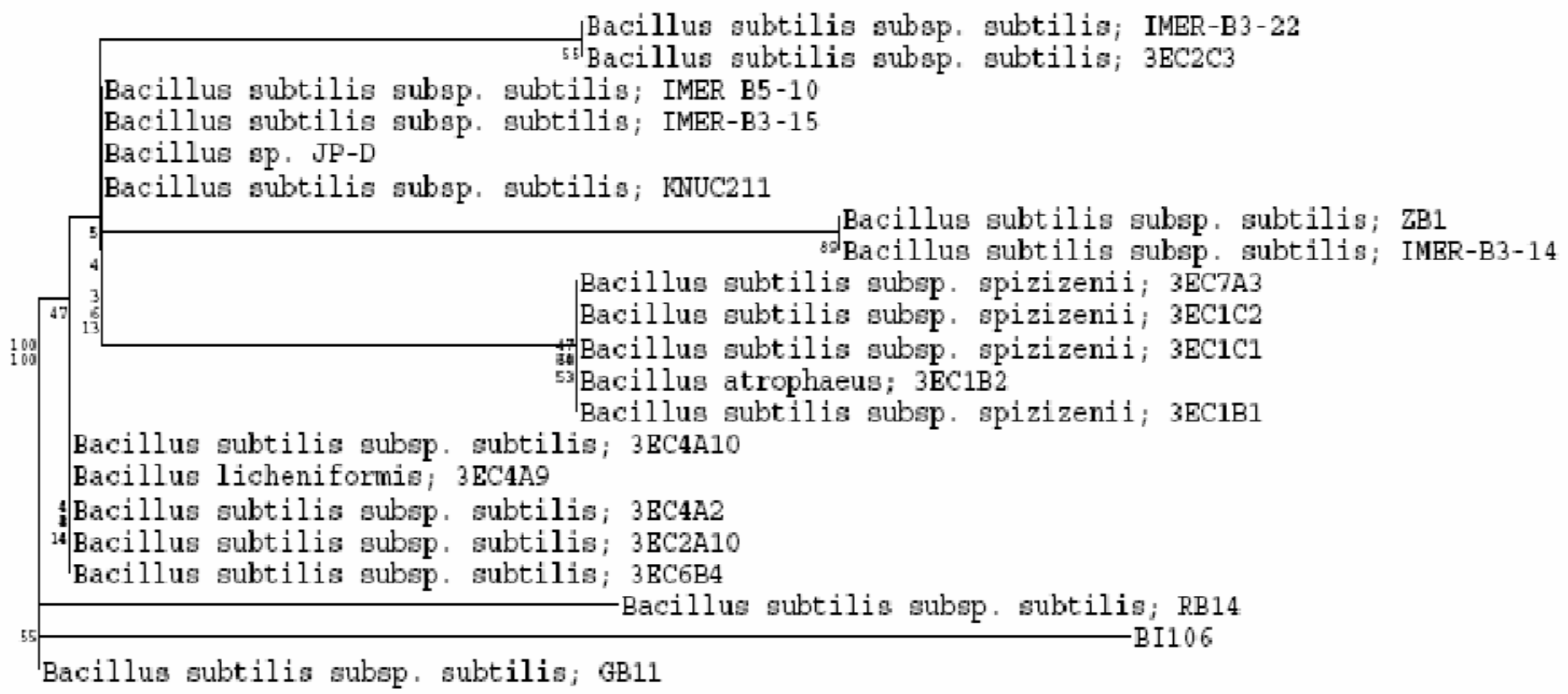

Scale: $\longmapsto$

Research article

CIndian Society for Education and Environment (iSee)
"Probiotic B. Subtilis"

http://www.indjst.org
Sreekumar \& Krishnan Indian J.Sci.Technol. 
Indian Journal of Science and Technology

this $B$. subtilis strain would have evolved to metabolize lactose. The sequencing data of this new strain has been submitted to National Centre for Biotechnology Information (NCBI), Europian Molecular Biology Laboratory (EMBL) and DNA Data Bank of Japan (DDBJ) and accepted for as new strain of Bacillus subtilis SKO9 NCBI-Genbank No:HM117721 (Sreekumar et al., 2010). This particular strain of Bacillus subtilis SKO9 can be used as a probiotic supplement in lactose intolerant people. The antibiotic susceptibility of this $B$. subtilis $S K O 9$ is of a very wide range and sensitive to most of the common antibiotics which makes it very safe for the use as a probiotic in human therapy for lactose intolerance.

Table 1. Antibiotic susceptibility of Probiotic spore forming Bacilli

\begin{tabular}{|l|c|}
\hline \multicolumn{1}{|c|}{$\begin{array}{c}\text { Antibiotic } \\
(\mu \mathrm{g})\end{array}$} & $\begin{array}{c}\text { Diameter of inhibition } \\
(\mathrm{mm})\end{array}$ \\
\hline Ampicillin $(10)$ & $22 \pm 1$ \\
\hline Gentamycin $(10)$ & $25 \pm 3$ \\
\hline Streptomycin $(10)$ & $21 \pm 3$ \\
\hline Erythromycin (15) & $26 \pm 0.5$ \\
\hline Clindamycin (2) & $20 \pm 1.5$ \\
\hline Tetracyclin (30) & $27 \pm 0.5$ \\
\hline Chloramphenicol (30) & $18 \pm 2$ \\
\hline Ciprofloxacin (5) & $33 \pm 0.5$ \\
\hline Amoxicillin (30) & $19 \pm 1$ \\
\hline Methicillin (5) & $24 \pm 3$ \\
\hline
\end{tabular}

\section{Reference}

1. Begley M, Hill C and Cormac GM (2006) Bile salt hydrolase activity in probiotics. Appl. Environ. Microbiol. 72 (3), 1729-1738.

2. Bruno WJ, Nicholas D Socci and Aaron L Halpern (2000) Weighted neighbor joining: A likelihood-based approach to distance-based phylogeny reconstruction. Mol. Biol. Evol. 17(1), 189-197.

3. Conway PL, Gorbach SL and Goldin BR (1987) Survival of lactic acid bacteria in the human stomach and adhesion to intestinal cells. J. Dairy Sci. 70, 1-12.

4. Crittenden RG and Playne MJ (1996) Production, properties and applications of food-grade oligosaccharides. Trend. Food Sci. Technol. 7, 353361.

5. De Vrese M and Stegelmann A (2001) Probiotics compensation for lactase insufficiency. Amer. J. Clinical Nutr. 73, 421S-429S.

6. Donkor ON, Henriksson A, Vasiljevic T and Shah NP (2006) Effect of acidification on the activity of probiotics in yoghurt during cold storage. Int. Dairy J. 16 (10), 1181-1189.

7. FAO/WHO (2002) Expert consultation: health and nutritional properties of probiotics in food including powder milk with live lactic acid bacteria. Cordoba (Argentina) (http://www.who.int/foodsafety/ publications/fs_management/probiotics/en/ oppure:
Vol. 3 No. 8 (Aug 2010)

ISSN: 0974- 6846

http://www.fao.org/es/ESN/food/foodandfood_probioc ons_en.stm)

8. Fuller R (1994) Probiotics: an overview. In: Human health: the contribution of microorganisms. Gibson SAW (ed.), Springer-Verlag, NY. pp: 63-73.

9. Harley S and Prescott M (2002) Laboratory exercises in microbiology. McGraw Hill. p:58.

10. Hyronimus B, Le Marrec C and Urdaci MC (1998) Coagulin, a bacteriocin-like inhibitory substance produced by Bacillus coagulans 14. J. Appl. Microbiol. $85,42-50$.

11.Khalid A, Rahim A and Bvong H Lee (1991) Specificity, inhibitory studies and oligosaccharide formation by P-galactosidase from psychrotrophic Bacillus subtilis KL88. J. Dairy. Sci. 74, 1773-1778.

12. Kim HS and Gilliland S (1983) L. acidophilus as a dietary adjunct for milk to aid lactose digestion in humans. J. Dairy Sci. 66, 959-966.

13.Lin M, Yen CL and Chen SH (1998) Management of lactose maldigestion by consuming milk containing Lactobacilli. Dig. Dis. Sci. 43, 133-137.

14. Nicholson W and Setlow P (1990) Molecular biological methods for Bacillus. Harwood C \& Cutting $S$ (eds.), John Wiley, NY. pp:391-450.

15.Pribila BA, Hertzler SR and Martin BR (2000) Improved lactose digestion and intolerance among African-American adolescent girls fed a dairy-rich diet. J. Amer. Dietetic Assoc. 100(5), 524-528; quiz 529-530.

16. Reva ON, Sorokulova IB and Smirnov VV (2001) Simplified technique for identification of the aerobic spore-forming bacteria by phenotype. Int. J. System. Evol. Microbiol. 51, 1361-1371.

17. Sneath PHA, Mair NS, Sharpe ME and Holt JG (1986) Endospore-forming gram-positive rods and cocci. In: Bergey's Manual of Systematic Bacteriology.

18.Sreekumar G and Soundarajan K (2010) Bacillus subtilis strain SK09, 16s ribosomal RNA gene sequence. In: Gene Bank, NCBI, freely available at http://www.ncbi.nlm.nih.gov/nuccore/297251625.

19.Szilagyi A, Malolepszy P and Yesovitch S (2007) Fructose malabsorption may be gender dependent and fails to show compensation by colonic adaptation. Dig. Dis. Sci. 52, 2999-3004.

20.Wayne PA (1997) National committee for clinical laboratory standards (NCCLS) performance standards for antimicrobial disk susceptibility tests, $6^{\text {th }}$ edn. Approved standard M2-A5. Nat. Comm. for Clinical Lab. Standards.

21. Weisburg WG, Barns SM, Pelletier DA and Lane DJ (1991) 16S ribosomal DNA amplification for phylogenetic study. J. Bacteriol. 173, 697-703.

22. Wiley EO, Brooks DR, Siegel-Causey D and Funk VA (1991) The compleat cladist: A primer of phylogenetic procedures. Univ. of Kansas Museum of Natural History, Spl. Publ. No. 19. pp:158.
Research article

CIndian Society for Education and Environment (iSee)
"Probiotic B. Subtilis"

http://www.indjst.org
Sreekumar \& Krishnan Indian J.Sci.Technol. 